\title{
BMJ Open Medication safety problems priorities in community pharmacy in Saudi Arabia: a multi-stakeholder Delphi study using the human factors framework
}

To cite: Al Juffali LA, Knapp P, Al-Aqeel S, et al. Medication safety problems priorities in community pharmacy in Saudi Arabia: a multi-stakeholder Delphi study using the human factors framework. BMJ Open 2019;9:e032419. doi:10.1136/ bmjopen-2019-032419

- Prepublication history and additional material for this paper are available online. To view these files, please visit the journal online (http://dx.doi org/10.1136/bmjopen-2019032419).

Received 18 June 2019 Revised 24 September 2019 Accepted 07 October 2019

Check for updates

(c) Author(s) (or their employer(s)) 2019. Re-use permitted under CC BY-NC. No commercial re-use. See rights and permissions. Published by BMJ.

${ }^{1}$ Clinical Pharmacy Department, College of Pharmacy, King Saud University, Riyadh, Saudi Arabia ${ }^{2}$ University of York and the Hull York Medical School, York, UK

${ }^{3}$ Strathclyde Institute of

Pharmacy and Biomedical

Sciences, University of

Strathclyde, Glasgow, UK

Correspondence to

Dr Lobna Abdullah Al Juffali;

laljaffali@ksu.edu.sa

\section{ABSTRACT}

Aim To achieve multi-stakeholder consensus and prioritisation of medication safety problems in community pharmacies in Saudi Arabia.

Design and intervention A theoretically-underpinned, three-round Delphi study.

Setting Saudi Arabia.

Participants Patients and public (pharmacy users), pharmacy-related professionals (policymakers, academics, medication safety officers and pharmacy owners) and community pharmacists.

Methods Round 1 comprised 84 statements derived from a qualitative study. The items were grouped according to the Human Factors Framework (HFF). Rounds 1 and 2 aimed to achieve consensus, 6-point Likert response scale (agreement/disagreement) was used. Round 3 aimed to prioritise the items for which consensus was achieved in Rounds 1 and 2 indicated on a 5-point scale (very important to unimportant). Consensus was predefined as any item that achieved $\geq 70 \%$.

Results The number of respondents in Rounds 1,2 and 3 was 161, 120 and 112, respectively. In all three rounds, the majority of respondents were pharmacy users (Round $177 \%(n=124)$, Round $274 \%(n=89)$, Round $372 \%$ $(n=81))$. Consensus was achieved with $28 / 84$ items. The top five medication safety priorities were: lack of pharmacy facilities such as counselling area, lack of communication between pharmacists and physicians, lack of patient databases, lack of post-registration pharmacist education and pharmacists' long working hours. The professional and pharmacy user groups achieved consensus on similar items through different categories of the HFFs. Community pharmacists had the highest percentage of consensus among the three groups for factors related to work, such as high workload and low salaries.

Conclusion This multi-stakeholder study used the HFF to identify and prioritise the main medication safety challenges facing community pharmacy in Saudi Arabia. It indicates the need for changes to practice and policy and further research to address these priorities and promote medication safety at an individual, pharmacy and population level.

\section{INTRODUCTION}

Community pharmacy is a complex system involving many interacting factors that
Strengths and limitations of this study

- It involved representatives of various stakeholders of community pharmacy including the public.

- The use of the HumanFactors Framework to categorise and prioritise medication safety problems equates to a universal language that can be understood in different healthcare disciplines and beyond the healthcare field

- Online surveys may be subject to selection bias

- A high percentage of pharmacy users chose 'I do not know' in Round 1 and 2.

- There was unequal representation from the three stakeholder groups in each of the three rounds.

influence medication safety. ${ }^{1-4}$ Medication safety is defined as 'freedom from accidental injury during the course of medication use; activities to avoid, prevent or correct adverse drug events, which may result from the use of medications'. ${ }^{5}$

In Saudi Arabia, community pharmacies continue to be product-oriented, despite the introduction of a patient-oriented model in the early 1970s. ${ }^{6}$ In 2018 the Saudi Ministry of Health $(\mathrm{MOH})$ started to enforce regulations about the supply of antibiotics without prescription with financial penalties of up to $£ 21000$, loss of pharmacy license and possible imprisonment for up to 6 months for pharmacists who violated this legislation. ${ }^{7}$ In 2019 the $\mathrm{MOH}$ launched an initiative to upgrade health services called 'Wasfati'. It allows the beneficiaries of free governmental health services (primary or secondary) to obtain medicines from the community pharmacy (private) closest to them at the right time and free of charge, instead of only from the outpatient pharmacy in the governmental hospitals as happened previously. ${ }^{8}$ While this initiative has created an opportunity to develop the community pharmacist role, it also generates medication safety concerns. ${ }^{1}$ The main medication safety 
problems identified in Saudi community pharmacy setting include commercial pressures, failure to enforce regulations, the fragmented healthcare system, self-medication with prescription-only medicines, inappropriate medication storage and excessive pharmacist workload. ${ }^{1}$

In order to develop strategies and interventions to address these diverse challenges, there was a need to prioritise which medication safety problems should be addressed. The Delphi method serves as a virtual meeting with a diverse group of experts to communicate and provide opinions on a practice-related matter. ${ }^{9}$

Various theories and frameworks, including the Human Factors Framework (HFF), have been identified to explore factors influencing patient safety ${ }^{10-15}$ and aid understanding of people's strengths and weaknesses, allowing design of better systems. ${ }^{16}$ The HFF incorporates a number of factors associated with the occurrence of safety problems such as those related to patients, individuals, teamwork, the work environment, the task, as well as managerial, organisational and external factors. Evidence shows that the HFF is efficient in aiding the identification of factors and the design of systems to promote patient safety. ${ }^{16}$ The HFF incorporates a universal language that can be understood by all patient safety stakeholders. It enables research findings to be communicated to various disciplines and ensures an understanding of medication safety challenges in the community pharmacy context. Furthermore, this means that identified challenges to medication safety can be compared with similar difficulties experienced by other disciplines and mutual experiences can then be shared.

The aim of this study, therefore, was to adopt a theoretically-underpinned approach to derive consensus and prioritise medication safety problems in community pharmacy in Saudi Arabia.

\section{METHODS}

\section{Study design}

A three-round Delphi study was conducted with three stakeholder groups (pharmacy users, 'professionals' and community pharmacists). A web-based Delphi study (e-Delphi) and a paper questionnaire were used concurrently depending on participant preference.

\section{Statement development}

The medication safety items included in Round 1 were derived from the results of an earlier study. ${ }^{1}$ A total of 119 statements was generated and categorised using the HFF (categories: external, organisational and management, work, physician, pharmacist, communication and information exchange, task, medication factors, patient behaviour and patient characteristics).

The Delphi items and response options were piloted with 15 individuals (five people from each of three groups; pharmacy users, professionals and community pharmacists). Their feedback indicated that the number of items was excessive. In addition, pharmacy users suggested adding an option 'I do not know' to the 5-point Likert scale. As a result of piloting, the total number of items was reduced to 84 statements (online supplementary table 1) (table 1).

\section{Determining consensus}

A 6-point Likert scale was used to rate the level of agreement/disagreement with each statement: strongly disagree, disagree, agree, strongly agree and 'I do not know'. Consensus was predefined as any item that reached $\geq 70 \%$ agreement (ie, 4 or 5 on the Likert scale) or disagreement (ie, 1 or 2 on the Likert scale). The cut point of $70 \%$ was based on published recommendations. ${ }^{17-20}$ A systematic review that investigated how consensus is operationalised in Delphi studies found that the definitions of consensus vary widely with $75 \%$ being the median threshold to define consensus and the range is $50 \%$ to $97 \% .^{17}$

\section{Participant identification and recruitment}

The aim was to recruit 25 participants in each group; the recommended average Delphi study panel size is 10 to 30 members. ${ }^{921}$ Participants were identified through a number of sources. Saudi adult pharmacy users were recruited using a range of methods. The social network Twitter, was used to recruit Saudis from a wide geographical area. A URL link to the study was tweeted to invite Saudis aged 18 years and over to participate. Non-Saudi nationals and individuals under 18 years of age were excluded. To ensure maximum variation in age, education level and other demographics, a snowballing recruitment technique was used. ${ }^{22}$ Individuals who agreed to participate were asked to invite other individuals of a different gender, age or educational level either personally or by re-tweeting the study link.

The 'professional' group in this study were those working in organisations that regulate and monitor community pharmacies, pharmacists and medicine supply in Saudi Arabia (ie, policymakers, academics, medication safety officers and pharmacy owners).

Table 1 Participants' responses by group across all rounds

\begin{tabular}{|c|c|c|c|c|c|c|}
\hline \multirow[b]{2}{*}{ Questionnaires } & \multicolumn{2}{|l|}{ Round 1} & \multicolumn{2}{|l|}{ Round 2} & \multicolumn{2}{|l|}{ Round 3} \\
\hline & No. sent & $\begin{array}{l}\text { Participants } \\
\% \text { (n) }\end{array}$ & No. sent & $\begin{array}{l}\text { Participants } \\
\% \text { (n) }\end{array}$ & No. sent & $\begin{array}{l}\text { Participants } \\
\% \text { (n) }\end{array}$ \\
\hline Pharmacy users & 284 & $43.6(124)$ & 119 & $74.7(89)$ & 119 & $68.0(81)$ \\
\hline Professionals & 37 & $32.4(12)$ & 12 & $91.6(11)$ & 12 & $83.3(10)$ \\
\hline Community pharmacists & 38 & $65.7(25)$ & 23 & $86(20)$ & 23 & $91.3(21)$ \\
\hline Total & 359 & $44.8(161)$ & 154 & $79.2(120)$ & 154 & 72.7 (112) \\
\hline
\end{tabular}


The professionals were recruited purposively through professional and personal networks.

Community pharmacists working in Riyadh, for a minimum of 1 year were eligible to participate. It is worth noting that all community pharmacists in Saudi Arabia are male and the majority are non-Saudi. In Saudi there are 20 governmental colleges of pharmacy and the majority of the Saudi graduate works in hospitals. Thus, $99 \%$ of community pharmacists are non-Saudi, with Egyptians being the predominant nationals. $^{23-31}$

They were selected purposively for the study to achieve a mix of pharmacists from five areas in Riyadh (north, west, east, south and the centre) and different types of pharmacies, including independent, clinic-affiliated and chain pharmacies.

Pharmacy users, professionals, community pharmacists participated in a previous focus group study were also invited to participate. ${ }^{1}$

All participants received the same invitation pack that included an invitation letter, a study information sheet and consent form. The invitations were followed by two reminders sent by email, WhatsApp or Twitter. The questionnaires were anonymised.

\section{Patient and public involvement}

Members of the public participated in this research, as they comprised one of the stakeholder groups. Members of the public were not invited to comment on the study design, were not consulted to develop patient relevant outcomes or interpret the results and were not invited to contribute to the writingoreditingofthismanuscriptforreadabilityoraccuracy.

\section{Round 1}

Rounds 1 and 2 aimed to achieve consensus on medication safety problems. Round 1 of the questionnaire contained two parts. Part 1 listed the medication safety problems statements. A space at the end of the list was provided to encourage participants to note any other problems related to medication safety and for general comments. Part 2 captured demographic data including (for professional and community pharmacists) years of experience, educational background, professional role and country of residence.

\section{Round 2}

Round 2 also comprised two parts. Part 1 summarised all statements for which consensus was achieved in Round 1. These items were presented as feedback to participants and no further responses were required to these items. Part 2 contained all Round 1 items that did not achieve consensus (not included in Part 1 list). No changes were made to the items apart from adding the feedback from Round 1 as a percentage alongside each statement.

\section{Round 3}

The purpose of Round 3 was to prioritise the medication safety problems for which consensus was achieved in Rounds 1 or 2. The stem of each consensus statement was modified: instead of asking participants about agreement, participants were asked to rate the importance of each item using a 5-point Likert scale, from 1 to 5: (1=very important to 5 =unimportant). Participants were also asked under each category, 'What are the most important medication safety problems in this category?'.

A pilot study was conducted for Round 3, the aim of which was to confirm whether participants understood the new stem question. Participants acknowledged the ease of the questionnaire. The average completion time for the Round 3 questionnaire was $20 \mathrm{~min}$ based on the pilot questionnaire.

\section{Questionnaire administration}

Each round was conducted over a maximum of 8 weeks: 3 weeks for response acquisition, and two reminders, as required, sent at 2 week intervals (figure 1 ). A closing date for each round was stated. Three weeks were set aside for analysing data and preparing for the subsequent round. The questionnaires were sent to all participants who completed Round 1, together with corresponding instructions for each round. After completing the questionnaire, participants were thanked and provided information about the next round. Participants were also asked about their preference for receiving the next round questionnaire, either by email or social media (WhatsApp or Twitter), which they could do confidentially and securely. To match the answers from participants across consecutive rounds, participants were asked to provide their mobile phone numbers as their unique identification number in all rounds. The questionnaire was developed in SurveyMonkey (SurveyMonkey Inc, San Mateo, California, USA) and its functioning pilot tested by the research team.

\section{Data analysis}

Data generated from the online version were extracted to Microsoft Excel for descriptive analysis (frequencies and percentages) to identify whether or not consensus had been obtained for each statement. Thematic analysis was performed on free text responses. The final ranking in Round 3 of the medication safety problem was weighted to account for the variation in stakeholder group size.

\section{RESULTS}

The Delphi study was conducted from January 2015 to May 2015. The total number of participants across the three groups was 166 (tables 1 and 2).

In Round 1 the majority of respondents across the three groups were from Riyadh ( $\mathrm{n}=130,80.7 \%)$. Fifty-two per cent of participants were female $(\mathrm{n}=84, \mathrm{n}=2$ missing), and the mean age was 35.4 (SD 11.5) years (table 3). For detailed demographics for each group see online supplementary tables 2, 3 and 4 .

\section{Consensus}

The total number of items for which consensus was achieved in each group after completion of Rounds 1 and 2 was 53 items in the pharmacy user group, 51 items in the professional group and 43 items in the community pharmacy 


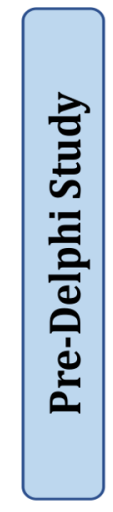

\section{Questionnaire development}

Generation of 119 items from focus groups [1]
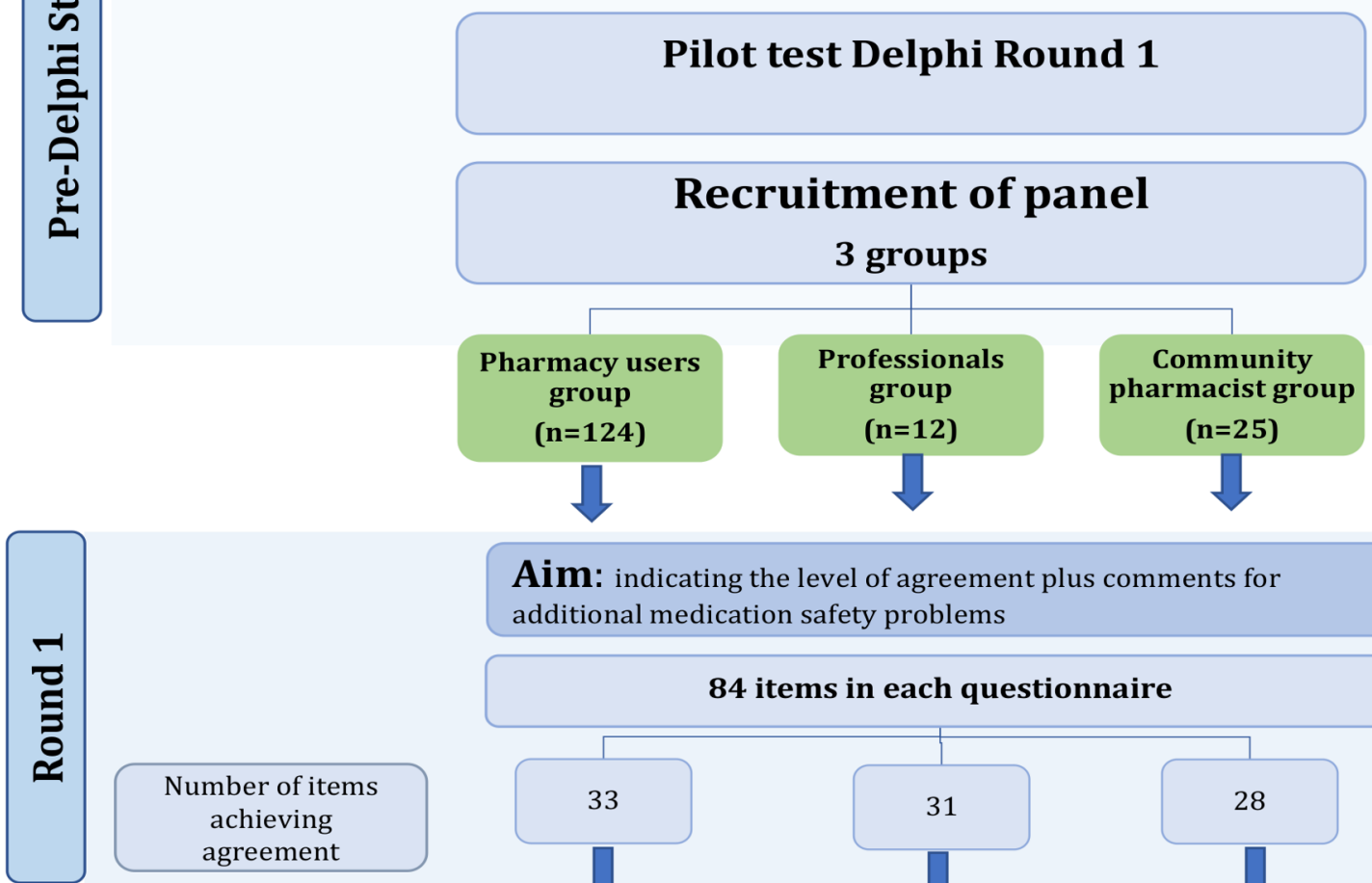

Aim: indicating the level of agreement plus comments for additional medication safety problems
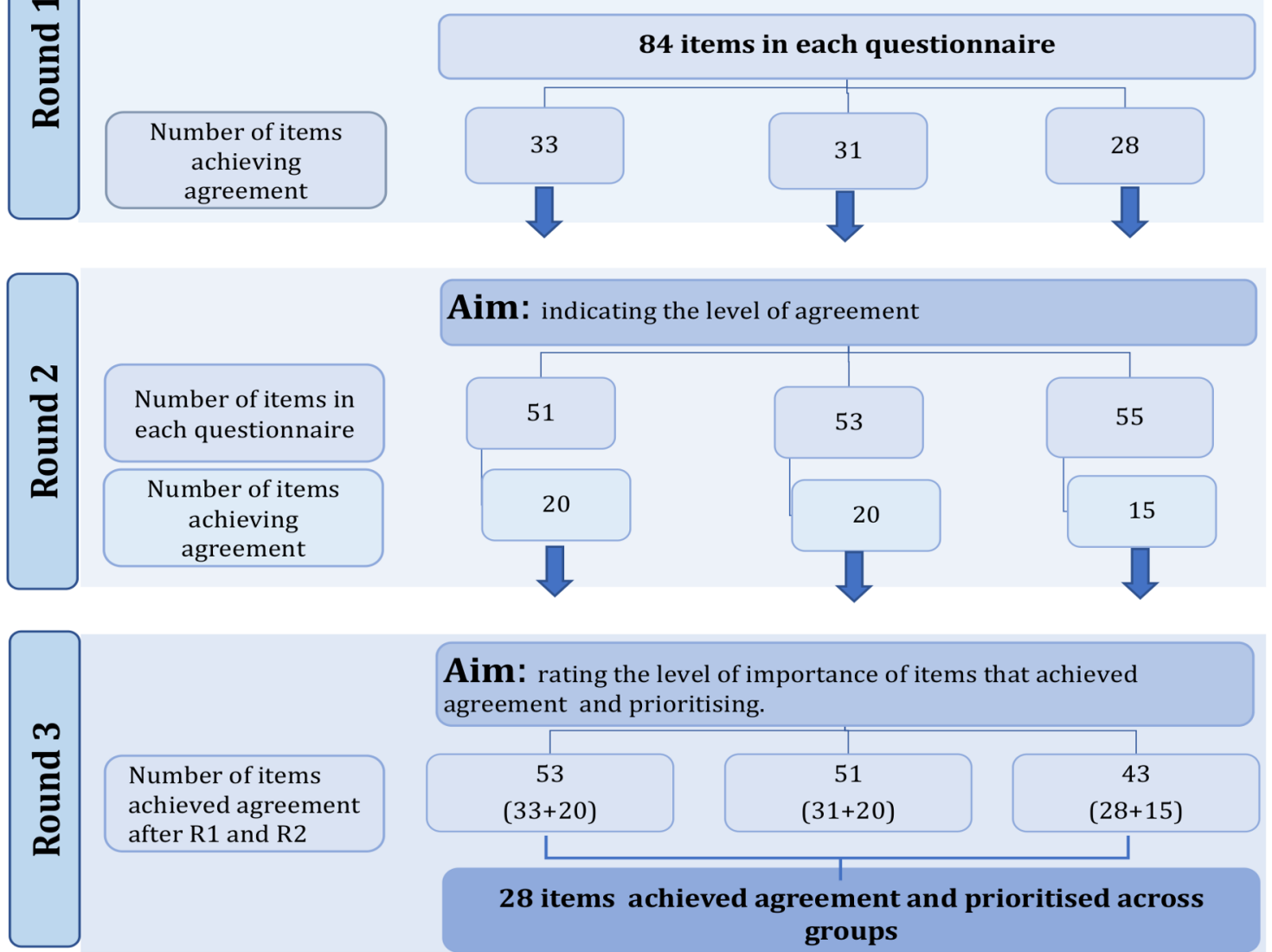

Figure 1 The Delphi process.

group (figure 1). Across the three stakeholder groups consensus was achieved with 28 items. The pharmacy users and professional groups agreed on 41 items $(47 \%$ of these items were related to external factors). However, community pharmacists achieved the lower levels of consensus on items related to external factors. No items under task factors and medication factors achieved consensus within the community pharmacy group. Table 4 shows items that reached consensus across the stakeholder groups.
Community pharmacists achieved consensus on all factors related to physician and patient behaviour and had the highest percentage of consensus among the three groups for factors related to work, such as high workload and low salaries. However, the pharmacy users group had the largest number of items achieving consensus related to task factors and medication. Professionals attributed problems to lack of coordination between regulators, commercial pressure and lack of enforcement of regulations. 
Table 2 Participants' completion rates across three rounds

Participants completion rate

\begin{tabular}{lc} 
Round number & $\%(\mathbf{n})$ \\
\hline $\mathrm{R} 1+\mathrm{R} 2+\mathrm{R} 3$ & $61(102)$ \\
$\mathrm{R} 1+\mathrm{R} 2$ & $8(13)$ \\
$\mathrm{R} 1+\mathrm{R} 3$ & $5(9)$ \\
$\mathrm{R} 2+\mathrm{R} 3$ & $0.6(1)$ \\
$\mathrm{R} 1^{*}$ & $22(37)$ \\
$\mathrm{R}^{*}$ & $2(4)$ \\
$\mathrm{R}^{*}$ & 0 \\
Total number of participants & 166 \\
\hline
\end{tabular}

${ }^{*}$ Responders who only responded to this round. R1, Round 1; R2, Round 2.

The community pharmacy group was the only group that did not achieve consensus on the general statement 'Medication safety problems in community pharmacies in Saudi Arabia are a major problem' (online supplementary table 5). Medication safety problems that did not achieve consensus and were excluded from Round 3 are available (online supplementary table 6). Five medication safety problems reached more than $70 \%$ disagreement (ie, 1 or 2 on the Likert scale) throughout the three rounds by the community pharmacy group (online supplementary table 7) meaning community pharmacists did not consider these medication safety problems as problems. The professional group also considered one of these items not a medication safety problem: "poor quality of medication in Saudi Arabia'.

Free text comments from respondents in Round 1 revealed no new themes. Examples of comments were the lack of enforcement of regulations and the lack of clear written Arabic information for patients.

\section{Prioritisation of consensus items}

The medication safety problems (28 items) (table 4) for which consensus was achieved across all groups were prioritised in Round 3 (figure 2). The item ranked number one in importance most often across the three groups was 'Pharmacies lacking facilities to provide different services such as counselling and compounding medication'; $58 \%$ of all participants ranked it as first. Table 5 shows the items prioritised based on stakeholder group and table 6 according to the HFF. All three groups achieved consensus on the same item under 'communication and information exchange': 'Patients not providing full information about their health condition'. The pharmacy users and the professional group prioritised the same items under the following HFF categories: organisational, work, task, patient behaviour and medication.

Table 3 Demographics of participants in Round 1

\begin{tabular}{|c|c|c|c|c|}
\hline & Pharmacy users & Professionals & $\begin{array}{l}\text { Community } \\
\text { pharmacists }\end{array}$ & Total \\
\hline Characteristic & $\%(n)$ & $\%(n)$ & $\%(n)$ & $\%(n)$ \\
\hline Number of participants R1 & 124 & 12 & 25 & 161 \\
\hline Gender - female & $64(79)$ & $41.6(5)$ & 0 & $52(84)$ \\
\hline Age (years.) mean (SD) & $35.8(12)$ & $37.8(13.6)$ & $32.4(7.1)$ & $35.4(11.5)$ \\
\hline \multicolumn{5}{|l|}{ Nationality } \\
\hline Saudi & $100(124)$ & $100(12)$ & 0 & $84.4(136)$ \\
\hline Non-Saudi & 0 & 0 & $100(25)$ & $15.5(25)$ \\
\hline \multicolumn{5}{|c|}{ Highest educational qualification } \\
\hline High school & $13(16)$ & 0 & 0 & $10(16)$ \\
\hline Bachelor's & $59(73)$ & $33(4)$ & $92(23)$ & $62(100)$ \\
\hline Master's & $19(24)$ & $42(5)$ & $8(2)$ & $19(31)$ \\
\hline $\mathrm{PhD}$ & $7(9)$ & 25(3) & 0 & $7(12)$ \\
\hline \multicolumn{5}{|l|}{ Geographical distribution } \\
\hline \multicolumn{5}{|l|}{ Central region } \\
\hline Riyadh & $76.7(95)$ & $83(10)$ & $100(25)$ & 80.7 (130) \\
\hline Al Qassim & $10.5(13)$ & - & - & $8.1(13)$ \\
\hline Hail & $1.6(2)$ & - & - & $1.2(2)$ \\
\hline Eastern region & $4.8(6)$ & $8(1)$ & - & $4.3(7)$ \\
\hline Western region & $2.4(3)$ & - & - & $1.9(3)$ \\
\hline Northern region & $0.8(1)$ & - & - & $0.6(1)$ \\
\hline Outside Saudi Arabia & $2.4(1)$ & $8(1)$ & - & $1.2(2)$ \\
\hline
\end{tabular}


Table 4 Medication safety problems which consensus was achieved across stakeholder groups after completing round 1 and 2

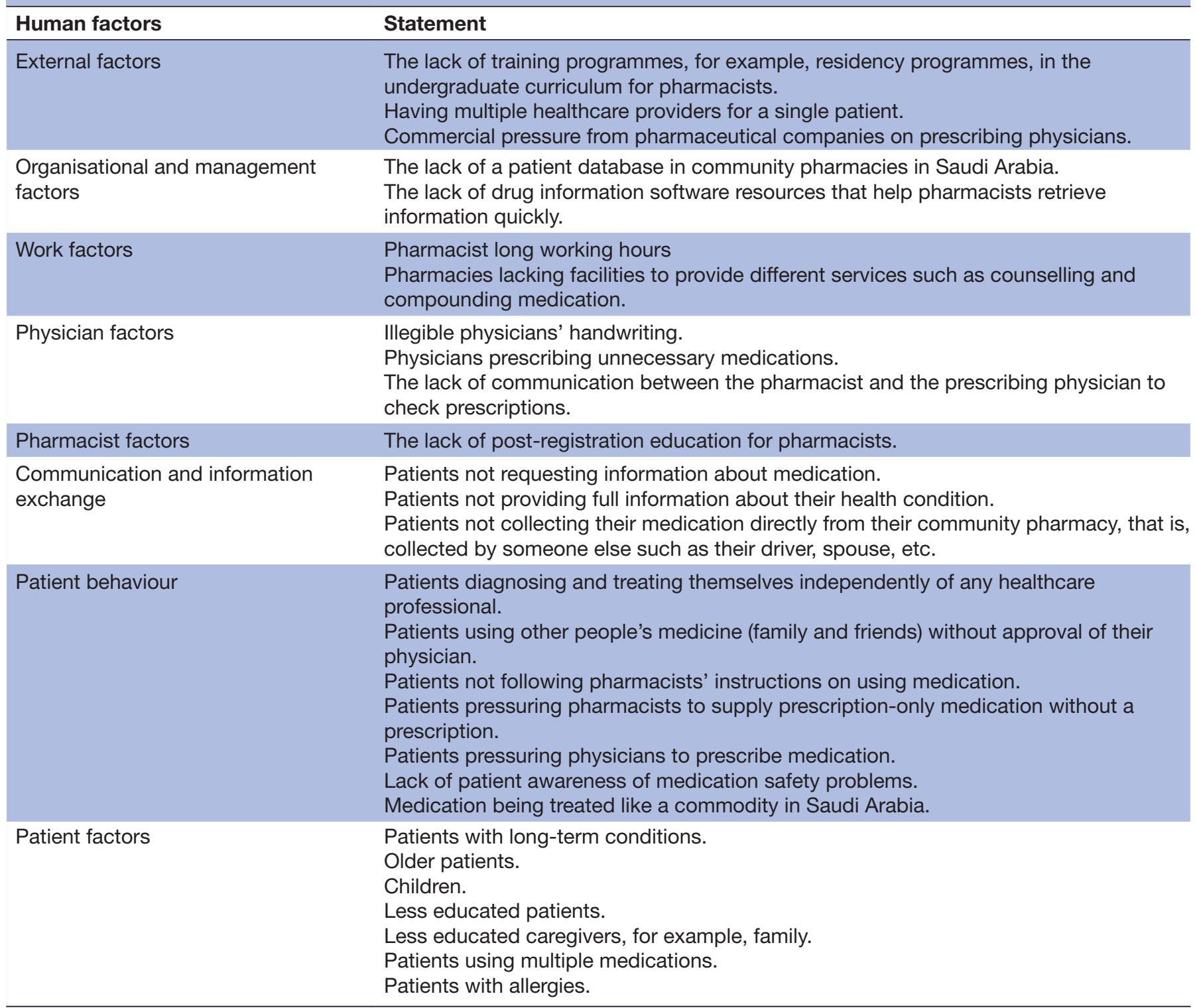

\section{DISCUSSION}

In this study a wide range of medication safety problems achieved consensus across the three groups. Medication safety problems were prioritised differently based on stakeholder group (table 5) and human factor category (table 6). The medication safety problem that was ranked highest across all groups was 'Pharmacies lacking facilities to provide different services such as counselling and compounding medication' (figure 2).

The top six prioritised items focused on pharmacy design, communication between pharmacists and physicians, patient databases, pharmacists' continuing education, pharmacists' working hours and unnecessary prescribing. These factors map to the following elements of the HFF: work, team, organisational and pharmacist factors. These have been identified as sociotechnical factors in other studies. ${ }^{2-4}$ Harvey et a ${ }^{3}$ explained that community pharmacy is a complex environment. Teams of people, processes, workloads, protocols, pharmacy resources, organisational systems, technical systems and space are involved. In order to understand safety problems, all factors have to be taken into account and the relationships between the teams of people and other components are important in dispensing safely. ${ }^{3}$

The design of the pharmacy was ranked as the number one priority as a medication safety problem across all groups. The layout of the pharmacy and lack of privacy can mean that it is difficult for patients to engage in conversation and share information with the community pharmacist, and for pharmacists to provide public health services and counselling. ${ }^{32-34}$ Privacy violations include overhearing conversations, medication being visible at the counter, calling out consumers' names to collect their medication and mentioning medicines by name. ${ }^{35}$ Pharmacies should be designed to provide full privacy and facilitate counselling in a private, comfortable space, ensuring proper information 
Pharmacies lacking facilities to provide different services. The lack of communication between the pharmacist and physician. The lack of a patient database in community pharmacies in Saudi Arabia.

The lack of post-registration education for pharmacists. Pharmacists' long working hours.

Physicians prescribing unnecessary medication. Patients not providing full information about their health condition. Lack of patient awareness of medication safety problems. Patients using multiple medications.

Patients diagnosing and treating themselves independently.

The lack of drug information software resources. Patients using other people's medicine ( without approval of their physician. Patients with long- term conditions. Illegible physicians' handwriting Less educated patients. Older patients. Children.

Patients not requesting information about medication. Patients not collecting their medication directly from their community pharmacy. The lack of a training program in the undergraduate curriculum for pharmacists.

Commercial pressure from pharmaceutical companies on physicians. Patients pressuring pharmacists to supply POM without a prescription. Less educated caregivers, e.g. family members. Patients with allergies. Patients not following pharmacists' instructions on using medication. Having multiple health care providers for a single patient. Medication being treated like a commodity in Saudi Arabia.

Patient pressuring physicians to prescribe medication.

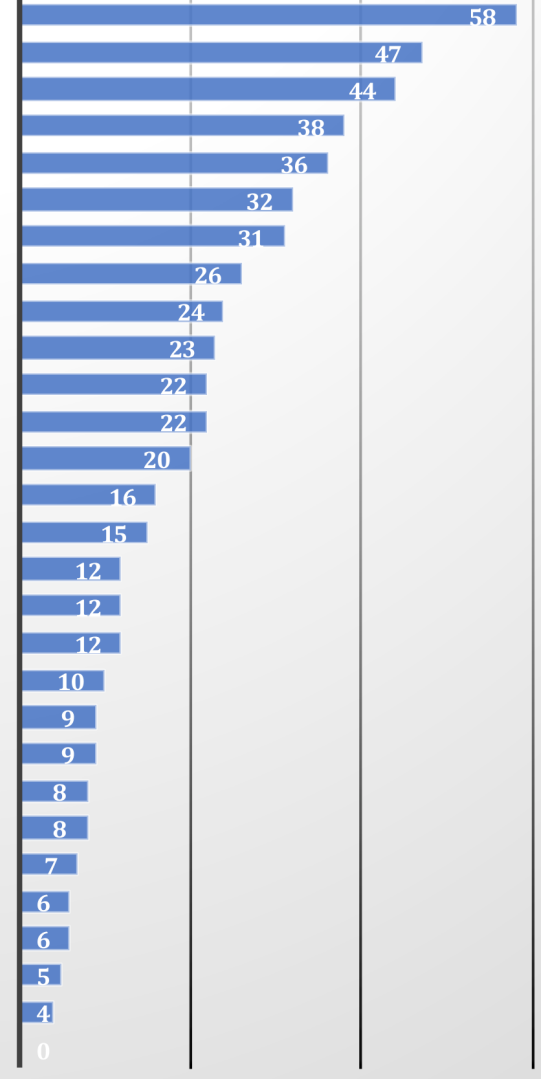

20

Percentage of responders rating medication safety problem as priority

Figure 2 Top ranked medication safety problems across all stakeholder group. POM, prescription only medication.

Table 5 Top five ranked medication safety problems by stakeholder group

\begin{tabular}{|c|c|c|c|}
\hline Rank & Pharmacy users & Professionals & Community pharmacists \\
\hline 1 & $\begin{array}{l}\text { Pharmacies lacking facilities to } \\
\text { provide different services such } \\
\text { as counselling and compounding } \\
\text { medication. }\end{array}$ & $\begin{array}{l}\text { Pharmacies lacking facilities to } \\
\text { provide different services such } \\
\text { as counselling and compounding } \\
\text { medication. }\end{array}$ & $\begin{array}{l}\text { The lack of drug information software } \\
\text { resources that help pharmacists } \\
\text { retrieve information quickly. }\end{array}$ \\
\hline 2 & $\begin{array}{l}\text { Lack of community pharmacists } \\
\text { adhering to regulations. }\end{array}$ & $\begin{array}{l}\text { Look-alike medication or sound-alike } \\
\text { medication, which are medicine brand } \\
\text { names that look or sound the same } \\
\text { as other medicine brand names when } \\
\text { written or spoken. }\end{array}$ & Pharmacists' long working hours. \\
\hline 3 & $\begin{array}{l}\text { The lack of communication between } \\
\text { the pharmacist and the prescribing } \\
\text { physician. }\end{array}$ & Patients using multiple medications. & $\begin{array}{l}\text { Patients not providing full information } \\
\text { about their health condition. }\end{array}$ \\
\hline 4 & $\begin{array}{l}\text { The lack of a patient database in } \\
\text { community pharmacies in Saudi } \\
\text { Arabia. }\end{array}$ & $\begin{array}{l}\text { The lack of a patient database in } \\
\text { community pharmacies in Saudi } \\
\text { Arabia. }\end{array}$ & $\begin{array}{l}\text { The lack of a patient database in } \\
\text { community pharmacies in Saudi } \\
\text { Arabia. }\end{array}$ \\
\hline 5 & $\begin{array}{l}\text { The lack of post-registration } \\
\text { education for pharmacists. }\end{array}$ & $\begin{array}{l}\text { The lack of knowledge of community } \\
\text { pharmacists. }\end{array}$ & $\begin{array}{l}\text { Commercial pressure from } \\
\text { pharmaceutical companies on } \\
\text { prescribing physicians. }\end{array}$ \\
\hline
\end{tabular}


Table 6 Prioritisation of medication safety problems according to the human factors framework across stakeholder groups

\begin{tabular}{|c|c|c|c|}
\hline Human factors & Pharmacy users & Professional & Community pharmacists \\
\hline External factors & $\begin{array}{l}\text { Having more than one regulatory body } \\
\text { to regulate community pharmacy in } \\
\text { Saudi Arabia, for example, Ministry } \\
\text { of Health and Saudi Food and Drug } \\
\text { Authority. }\end{array}$ & $\begin{array}{l}\text { The lack of enforcement of regulations } \\
\text { by the Ministry of Health. }\end{array}$ & $\begin{array}{l}\text { Commercial pressure from } \\
\text { pharmaceutical companies on } \\
\text { prescribing physicians. }\end{array}$ \\
\hline $\begin{array}{l}\text { Organisational and } \\
\text { management factors }\end{array}$ & $\begin{array}{l}\text { The lack of a patient database in } \\
\text { community pharmacies in Saudi } \\
\text { Arabia. }\end{array}$ & $\begin{array}{l}\text { The lack of a patient database in } \\
\text { community pharmacies in Saudi } \\
\text { Arabia. }\end{array}$ & $\begin{array}{l}\text { The lack of drug information software } \\
\text { resources that help pharmacists } \\
\text { retrieve information quickly. }\end{array}$ \\
\hline Work factors & $\begin{array}{l}\text { Pharmacies lacking facilities to provide } \\
\text { different services such as counselling } \\
\text { and compounding medication. }\end{array}$ & $\begin{array}{l}\text { Pharmacies lacking facilities to provide } \\
\text { different services such as counselling } \\
\text { and compounding medication. }\end{array}$ & Pharmacists' long working hours. \\
\hline Physician factors & $\begin{array}{l}\text { The lack of communication between } \\
\text { the pharmacist and the prescribing } \\
\text { physician to check prescriptions. }\end{array}$ & $\begin{array}{l}\text { Physicians prescribing unnecessary } \\
\text { medication. }\end{array}$ & Illegible physicians' handwriting. \\
\hline Task factors & $\begin{array}{l}\text { Supplying prescription medication to } \\
\text { patients without a prescription. }\end{array}$ & $\begin{array}{l}\text { The lack of proper labelling of } \\
\text { medication from medications supplied } \\
\text { from community pharmacies. }\end{array}$ & \\
\hline \multirow{3}{*}{$\begin{array}{l}\text { Communication } \\
\text { and information } \\
\text { exchange }\end{array}$} & \multirow[t]{3}{*}{$\begin{array}{l}\text { Patients not providing full information } \\
\text { about their health condition. }\end{array}$} & $\begin{array}{l}\text { Patients not providing full information } \\
\text { about their health condition. }\end{array}$ & \multirow[t]{3}{*}{$\begin{array}{l}\text { Patients not providing full information } \\
\text { about their health condition. }\end{array}$} \\
\hline & & $\begin{array}{l}\text { The lack of information provided by } \\
\text { pharmacists in the form of counselling. }\end{array}$ & \\
\hline & & $\begin{array}{l}\text { The lack of clear, understandable } \\
\text { spoken medication information in } \\
\text { Arabic provided to patients. }\end{array}$ & \\
\hline Patient behaviour & $\begin{array}{l}\text { Lack of patient awareness of } \\
\text { medication safety problems. }\end{array}$ & $\begin{array}{l}\text { Lack of patient awareness of } \\
\text { medication safety problems. }\end{array}$ & $\begin{array}{l}\text { Patients diagnosing and treating } \\
\text { themselves independently of any } \\
\text { healthcare professional. }\end{array}$ \\
\hline $\begin{array}{l}\text { Patient } \\
\text { characteristics }\end{array}$ & Patients with long-term conditions. & Patients using multiple medications. & Older patients. \\
\hline
\end{tabular}

exchange and the safe supply of medication. Dedicated locations should be available for all services provided, such as vaccinations and other public health services.

Poor physical pharmacy design contributes to other medication safety challenges, such as dispensing errors. ${ }^{46}$ Pharmacy layout is an important factor in ensuring a reduction in work stress and interruptions. ${ }^{37}$ A spaciously designed pharmacy allows easy movement and workflow, potentially contributing to a reduction in pharmacist stress and dispensing errors. ${ }^{37}$

An interesting finding of the current study is the seventh item prioritised under the patient factor 'Patients not providing full information about their health condition'. A limited number of studies have identified the context of this behaviour and its impact on patient safety. ${ }^{21} 22$ One possible explanation is that research on medication safety problems in community pharmacy has tended to focus on sociotechnical factors with very limited data on patient behaviour. ${ }^{8-10}$ Further inquiry is needed to understand the reasons for such behaviour from the viewpoints of pharmacy users, through understanding their attitudes and perceptions towards sharing information with pharmacy personnel.

The community pharmacist group considered five items not to be medication safety problems; 'Generic substitution' was one of the five items, in contrast to the pharmacy users' group and professional who categorised it as a medication safety.

Patient insecurity due to generic substitution was reported as one of the major causes of drug-related problems related to medication supplied by community pharmacies in Germany. ${ }^{38}$ Further research is needed to understand the attitudes and concerns of pharmacy users to generic medication. Possible reasons identified in an earlier study include worries about medication quality and the pharmacist's knowledge. ${ }^{1}$ In addition, research is needed to understand community pharmacists attitudes regarding supplying and counselling generic medication. 


\section{Study implications}

A number of measures have been taken in Saudi Arabia to ensure the safe supply and use of medication from community pharmacies, such as enforcement of regulations and establishing a national electronic patient database, ${ }^{78}$ but further areas for improvements are needed. This study prioritisation exercise could be used as a 'road map' for designing a systematic approach to improving medication safety in community pharmacy in Saudi Arabia. The findings could aid organisations responsible for the regulation of community pharmacy to target key problems and set future research priorities based on stakeholder perspective and human factors categories.

The study supports the use of HFF to understand the medication safety problems in community pharmacy. It would be useful to explore the use of HFF in community pharmacy outside the Saudi context.

\section{Strengths and limitations of this study}

The main strength of this study is that it involved representatives of various stakeholders of community pharmacy in defining medication safety problems, achieving consensus and prioritisation of these factors. This has provided comprehensiveness of the medication safety problems evident by no further medication safety problems being identified in the open-ended question asked in Round 1.

The HFF facilitated the categorisation and understanding of the medication safety problems. In addition, it provided theoretical underpinning to this study. ${ }^{39}$ The use of theory helps to guide research adds context and provides in-depth description, interpretation and explanation. ${ }^{39}$

Using the option of an online questionnaire helped to minimise missing data and facilitate the speed in administrating the questionnaires through the three rounds. The attrition rate in later rounds, which is often a problem in Delphi studies, was very not substantial. ${ }^{40}$

However, there are a number of limitations with this study. First, the use of online questionnaires restricts participation to those who have internet access and computer skills. Second, we used social media to recruit pharmacy users. Saudi Arabia is the country with the highest number of active Twitter users in the Arab region (2.4million users), accounting for more than $40 \%$ of the region's active Twitter users. ${ }^{41}$ This helped to recruit pharmacy users from different geographical areas in Saudi Arabia, which might increase the chances of generalisability of the results. The snowballing technique and the use of WhatsApp also helped to reach a wider population. Nevertheless, using social media may introduce selection bias

Third, the majority of responders were from Riyadh city, the capital of Saudi Arabia, where 25\% of the Saudi population live. ${ }^{42}$ Although Riyadh residents come from different parts of Saudi Arabia, their views might not be representative of people across Saudi Arabia.

Fourth, the pharmacy user group participants were young adults with Bachelor degrees and their responses may differ from less educated or elderly individuals. However, it worth noting that $65 \%$ of the Saudi population is under the age of 40 years and $23 \%$ have college degrees. ${ }^{42}$

Fifth, a high percentage of pharmacy users chose 'I do not know' during Rounds 1 and 2 possibly as several statements in these two rounds were related to community pharmacy regulations.

Finally, unequal proportion of participants through the three rounds in each stakeholder group. Pharmacy users were over-represented ( $\mathrm{n}=124)$ while only 12 'professionals' participated. Different sampling techniques was used for each group. We used convenient sampling to recruit 37 professional and only 12 responded. Low participation rates may have been due to time constraints and work pressures.

As for the pharmacy user group, previous experience with flyers and notices in community centres and community pharmacies showed low response rate so we used social media to recruit. ${ }^{1}$ There was a high number of respondents exceeding our expectations of only 25 and we decided not to exclude.

Stakeholder responses were treated equally through all three rounds, but the final ranking of the medication safety problem was weighted to account for the variation in stakeholder group size.

\section{CONCLUSION}

This study identified the medication safety priorities affecting current community pharmacy practice among three stakeholder groups in Saudi Arabia. The lack of facilities to provide different services, such as counselling, was the most important problem agreed by all three groups, followed by the failure of communication between physicians and community pharmacists, and the lack of a patient database in community pharmacy. Each stakeholder group had different perspectives on medication safety, demonstrating the importance of exploring and including different stakeholder perspectives on topics of such importance.

Twitter Lobna Abdullah Al Juffali @lobnaaljuffali

Acknowledgements The authors would like to thank the participants in the study. Also special thanks to Dr Yvonne Hopf and Professor Cris Ryan for sharing their valuable experiences with Delphi studies, which guided my research design.

Contributors LA, MW, SA and PK were involved in all stages of the study. LA drafted the article, and all authors were involved in critical revisions and approved the final version.

Funding This research project was supported by a grant from the "Research Centre of Female Scientific and Medical Colleges", Deanship of Scientific Research, King Saud University.

Competing interests None declared.

Patient consent for publication Obtained.

Ethics approval The College Ethics Review Board of the University of Aberdeen approved this study (CERB/2014/5/1044).

Provenance and peer review Not commissioned; externally peer reviewed.

Data availability statement All data relevant to the study are included in the article or uploaded as supplementary information.

Open access This is an open access article distributed in accordance with the Creative Commons Attribution Non Commercial (CC BY-NC 4.0) license, which permits others to distribute, remix, adapt, build upon this work non-commercially, and license their derivative works on different terms, provided the original work is 
properly cited, appropriate credit is given, any changes made indicated, and the use is non-commercial. See: http://creativecommons.org/licenses/by-nc/4.0/.

ORCID iD

Sinaa Al-Aqeel http://orcid.org/0000-0003-0571-7230

\section{REFERENCES}

1 Al Juffali L, Al-Aqeel S, Knapp P, et al. Using the human factors framework to understand the origins of medication safety problems in community pharmacy: a qualitative study. Res Social Adm Pharm 2019;15:558-67.

2 Phipps DL, Noyce PR, Parker D, et al. Medication safety in community pharmacy: a qualitative study of the sociotechnical context. BMC Health Serv Res 2009;9:158.

3 Harvey J, Avery AJ, Ashcroft D, et al. Exploring safety systems for dispensing in community pharmacies: focusing on how staff relate to organizational components. Res Social Adm Pharm 2015;11:216-27.

4 Szeinbach S, Seoane-Vazquez E, Parekh A, et al. Dispensing errors in community pharmacy: perceived influence of sociotechnical factors. Int J Qual Health Care 2007;19:203-9.

5 Committee of Experts on Management of Safety and Quality in Health Care. Glossary of terms related to patient and medication safety. expert group on safe medication practices, 2005. Available: http://www.bvs.org.ar/pdf/seguridadpaciente.pdf [Accessed 31 May 2017].

6 Al-Arifi MN, Al-Dhuwaili AA, Gubara OA, et al. Pharmacists' understanding and attitudes towards pharmaceutical care in Saudi Arabia. Saudi Pharm J 2007;15:146-59.

7 Ministry of Health. MOH Warns against Selling antibiotics without prescription, 2018. Available: https://www.moh.gov.sa/en/Ministry/ MediaCenter/News/Pages/news-2018-04-17-004.aspx [Accessed 22 May 2019].

8 Ministry of Health, Kingdom Saudi Arabia. E-Prescription service, 2019. Available: https://www.moh.gov.sa/en/eServices/Pages/ Prescriptions.aspx [Accessed 28 May 2019].

9 Powell C. The Delphi technique: myths and realities. J Adv Nurs 2003;41:376-82.

10 Carayon P, Xie A, Kianfar S. Human factors and ergonomics as a patient safety practice. BMJ Qual Saf 2014;23:196-205.

11 Taylor-Adams S, Vincent C, Street P. Systems analysis of clinical incidents: the London protocol. Clin Risk 2004;10:211-20.

12 Carayon P, Schoofs Hundt A, Karsh B-T, et al. Work system design for patient safety: the SEIPS model. Qual Saf Health Care 2006;15 Suppl 1:i50-8.

13 Lawton R, McEachan RRC, Giles SJ, et al. Development of an evidence-based framework of factors contributing to patient safety incidents in hospital settings: a systematic review. BMJ Qual Saf 2012;21:369-80.

14 World Health Organisation. The world health report 2000. Health systems: improving performance. Geneva WHO; 2000. http://www. who.int/whr/2000/en/

15 Henriksen K, Dayton E, Keyes MA. Understanding adverse events: a human factors framework. In: Hughes RG, ed. Patient safety and quality: an evidence-based Handbook for nurses. US: Rockville (MD: Agency for Healthcare Research and Quality, 2008: 1-17.

16 Carayon P. Handbook of human factors and ergonomics in health care and patient safety. USA: CRC Press, 2011. ISBN: 9781138074590.

17 Diamond IR, Grant RC, Feldman BM, et al. Defining consensus: a systematic review recommends methodologic criteria for reporting of Delphi studies. J Clin Epidemiol 2014;67:401-9.

18 Vogel C, Zwolinsky S, Griffiths C, et al. A Delphi study to build consensus on the definition and use of big data in obesity research. Int J Obes 2019;390.

19 Slade SC, Dionne CE, Underwood M, et al. Standardised method for reporting exercise programmes: protocol for a modified Delphi study. BMJ Open 2014;4:e006682.
20 Henderson EJ, Rubin GP. Development of a community-based model for respiratory care services. BMC Health Serv Res 2012;12:193.

21 Boulkedid R, Abdoul H, Loustau M, et al. Using and reporting the Delphi method for selecting healthcare quality indicators: a systematic review. PLoS One 2011;6:e20476.

22 Keeney S, Hasson F, McKenna H. The Delphi technique in nursing and health research. Wiley-Blackwell, 2011. ISBN: 9781444392029

23 Al-Hassan M. Community Pharmacy Practice in Saudi Arabia:An Overview. The Internet Journal of Pharmacology 2011;9.

24 Al-Ghamdi MS. Continuing pharmaceutical education for community pharmacists in the eastern Province of Saudi Arabia. J Family Community Med 2001;8:45-52.

25 Khan TM, Azhar S. A study investigating the community pharmacist knowledge about the appropriate use of inhaler, eastern region AlAhsa, Saudi Arabia. Saudi Pharm J 2013;21:153-7.

26 Al-Mohamadi A, Badr A, Bin Mahfouz L, et al. Dispensing medications without prescription at Saudi community pharmacy: extent and perception. Saudi Pharmaceutical Journal 2013;21:13-18.

27 Al-Rukban MO, Rizvi MR. Pharmacist's knowledge, attitude and practices towards written prescription in dispensing and substitution of drugs in Riyadh. Majmaah J Health Sciences 2014;2:28-34.

28 Bahnassi A. Pharmacists views and practices in regard to sales of antibiotics without a prescription in Madinah, Saudi Arabia. J Patient Saf 2016;12:159-64.

29 Bahnassi A. Do no harm: the role of community pharmacists in regulating public access to prescription drugs in Saudi Arabia. Int $J$ Pharm Pract 2016;24:142-5.

30 Hadi MA, Karami NA, Al-Muwalid AS, et al. Community pharmacists' knowledge, attitude, and practices towards dispensing antibiotics without prescription (DAwP): a crosssectional survey in Makkah Province, Saudi Arabia. Int J Infect Dis 2016;47:95-100

31 Alkhuzaee FS, Almalki HM, Attar AY, et al. Evaluating community pharmacists' perspectives and practices concerning generic medicines substitution in Saudi Arabia: a cross-sectional study. Health Policy 2016;120:1412-9.

32 Saramunee K, Krska J, Mackridge A, et al. How to enhance public health service utilization in community pharmacy?: general public and health providers' perspectives. Res Social Adm Pharm 2014;10:272-84

33 Eades CE, Ferguson JS, O'Carroll RE. Public health in community pharmacy: a systematic review of pharmacist and consumer views. BMC Public Health 2011;11:582.

34 Hassell K, Rogers A, Noyce P. Community pharmacy as a primary health and self-care resource: a framework for understanding pharmacy utilization. Health Soc Care Community 2000;8:40-9.

35 Hattingh HL, Emmerton L, Ng Cheong Tin P, et al. Utilization of community pharmacy space to enhance privacy: a qualitative study. Health Expect 2016;19:1098-110.

36 Harvey J, Avery AJ, Waring J, et al. The socio-technical organisation of community pharmacies as a factor in the electronic prescription service release two implementation: a qualitative study. BMC Health Serv Res 2012;12:471.

37 Jacobs S, Hassell K, Johnson S. Managing workplace stress to enhance safer practice in community pharmacy: a scoping study. Pharmacy Research UK 2013:1-139.

38 Nicolas A, Eickhoff C, Griese N, et al. Drug-Related problems in prescribed medicines in Germany at the time of dispensing. Int $J$ Clin Pharm 2013;35:476-82.

39 Kelly M. The role of theory in qualitative health research. Fam Pract 2010:27:285-90.

40 de Villiers MR, de Villiers PJT, Kent AP. The Delphi technique in health sciences education research. Med Teach 2005;27:639-43.

41 Arab social media report. Twitter in the Arab region, 2014. Available: http://www.arabsocialmediareport.com/Twitter/LineChart.aspx?\& PriMenulD=18\&Cat|D=25\&mnu=Cat [Accessed 27 Dec 2016].

42. Kingdom of Saudi Arabia, General Authority for Statistics, 2018. Annual statistical yearbook,54.. Available: https://www.stats.gov.sa/ en/1007-0 [Accessed October/16, 2019]. 